\title{
A murine model of autosomal dominant neurohypophyseal diabetes insipidus reveals progressive loss of vasopressin-producing neurons
}

\author{
Theron A. Russell, Masafumi Ito, Mika Ito, Richard N. Yu, Fred A. Martinson, \\ Jeffrey Weiss, and J. Larry Jameson
}

Division of Endocrinology, Metabolism, and Molecular Medicine, Northwestern University Feinberg School of Medicine, Chicago, Illinois, USA

\begin{abstract}
Familial neurohypophyseal diabetes insipidus (FNDI) is an autosomal dominant disorder caused by mutations in the arginine vasopressin (AVP) precursor. The pathogenesis of FNDI is proposed to involve mutant protein-induced loss of AVP-producing neurons. We established murine knock-in models of two different naturally occurring human mutations that cause FNDI. A mutation in the AVP signal sequence $[\mathrm{A}(-1) \mathrm{T}]$ is associated with a relatively mild phenotype or delayed presentation in humans. This mutation caused no apparent phenotype in mice. In contrast, heterozygous mice expressing a mutation that truncates the AVP precursor (C67X) exhibited polyuria and polydipsia by 2 months of age and these features of DI progressively worsened with age. Studies of the paraventricular and supraoptic nuclei revealed induction of the chaperone protein $\mathrm{BiP}$ and progressive loss of AVP-producing neurons relative to oxytocin-producing neurons. In addition, Avp gene products were not detected in the neuronal projections, suggesting retention of WT and mutant AVP precursors within the cell bodies. In summary, this murine model of FNDI recapitulates many features of the human disorder and demonstrates that expression of the mutant AVP precursor leads to progressive neuronal cell loss.
\end{abstract}

J. Clin. Invest. 112:1697-1706 (2003). doi:10.1172/JCI200318616.

\section{Introduction}

Familial neurohypophyseal diabetes insipidus (FNDI) is an autosomal dominant disorder caused by a deficiency of the antidiuretic hormone arginine vasopressin (AVP) (1). Symptoms of diabetes insipidus, such as polyuria, polydipsia, and thirst, usually manifest several months or years after birth. A limited number of autopsy studies have reported a paucity of AVP-producing neurons in the hypothalamus of patients with FNDI (2-5), leading to the hypothesis that progressive degeneration of AVP-producing cells might be involved in the pathogenesis of the disease.

The AVP precursor (preproAVP) is synthesized in magnocellular neurons of the hypothalamus and is converted to proAVP by the removal of the signal peptide and

Received for publication April 10, 2003, and accepted in revised form September 30, 2003.

Address correspondence to: J. Larry Jameson, Department of Medicine, Northwestern University Feinberg School of Medicine, Galter Pavilion Suite 3-150, 251 East Huron Street, Chicago, Illinois 60611, USA. Phone: (312) 926-9436; Fax: (312) 926-7260; E-mail: ljameson@northwestern.edu.

Theron A. Russell and Masafumi Ito contributed equally to this work.

Conflict of interest: The authors have declared that no conflict of interest exists.

Nonstandard abbreviations used: familial neurohypophyseal diabetes insipidus (FNDI); arginine vasopressin (AVP); neurophysin II (NPII); knock in (KI); oxytocin (OT); paraventricular nucleus (PVN). the addition of carbohydrate side chains within the ER. After trafficking to the Golgi apparatus, precursors are further glycosylated and packaged into dense core granules. Subsequent proteolytic processing during axonal transport to the posterior pituitary results in the generation of AVP, neurophysin II (NPII), and glycoprotein, all of which are stored within neurosecretory vesicles in the nerve terminals and released into the blood in response to osmotic stimuli (6). AVP then binds to the V2-type receptors in the kidney and controls serum osmolality by reducing renal water excretion.

In patients with FNDI, a number of distinct mutations have been found in the AVP gene (7) that encodes the AVP precursor (8-34). Most of the mutations occur within the signal peptide and the NPII domain (35). Among the signal peptide mutations, a substitution of threonine for alanine at the -1 position $[\mathrm{A}(-1) \mathrm{T}]$ has been reported in several different ethnic groups $(10,12,13,24)$. In the NPII domain, a number of different mutations have been identified, including missense mutations, nonsense mutations, and a single amino acid deletion. For the most part, genotype-phenotype correlations are not apparent, and most mutations lead to a similar clinical presentation, although there is some variation even within the same family. An exception, however, is the A(-1)T signal peptide mutation, which is frequently associated with delayed-onset or milder DI (35).

Because FNDI is a dominant disorder in which one allele is normal, it has been suggested that the mutant 
protein leads to AVP deficiency either by interfering directly with processing of the normal protein or by causing cellular toxicity, or both. In vitro experiments have been used to investigate the processing and cellular effects of transfected AVP mutants (36-39). Mutant AVP precursors are retained in the ER, leading to altered protein processing (36-39) and cell toxicity (36). In addition, when WT and mutant AVP precursors are coexpressed, the mutant protein impairs the trafficking of WT precursors by forming dimers, suggesting a classic dominant negative mechanism (40). These two mechanisms - ER retention and cytotoxicity and formation of mutant/WT complexes - are not mutually exclusive, and together might explain the delayed onset of the disease and the fact that DI occurs despite the presence of a normal allele.

Because studies of pathogenesis are limited in humans, we sought to develop a murine model to analyze the function of AVP-producing neurons in FNDI. We used a targeted gene knock-in (KI) approach rather than transgenic expression of the Avp gene, reasoning that gene dosage and normal regulation of the endogenous gene might be important variables in disease pathogenesis. Two KI models were created, each harboring a different point mutation reported in humans. The first mutation is the $\mathrm{A}(-1) \mathrm{T}$ signal peptide mutation, which causes inefficient cleavage of the signal peptide by signal peptidase (10) and a relatively mild phenotype in humans (35). The other mutation is a C67X nonsense mutation that produces an AVP precursor truncated within the NPII domain (15). The expression of this nonsense mutation in cultured cells resulted in

\section{Figure 1}

Targeted mutagenesis of the mouse Avp gene. (a) Targeting strategy. Specific mutations and restriction sites were inserted into exon 1 $[\mathrm{A}(-1) \mathrm{T}$; Scal] or exon 2 [C67X; Nhel] by homologous recombination. An additional Xbal site $\left(X^{*}\right)$ is created after Cre excision of the loxP-Neo-loxP cassette from the $\mathrm{A}(-1) \mathrm{T}$ targeted allele. Introduced restriction sites were used to detect mutant and WT Avp genes and reverse-transcribed Avp mRNA. White boxes, Avp gene exons; gray boxes, Oxt gene exons. X, Xbal; H, HindIII; E, EcoRI; A, Accl. (b) Southern blot analysis. Xbal- and Scal-digested genomic DNA was hybridized with a 1,214-bp probe (HindIII-EcoRI DNA fragment), labeling a 2,375-bp Xbal-digested DNA for the normal allele and 1,507-bp (Xbal-Scal) and 404-bp (Scal-Xbal*) fragments for the $A(-1) \top$ mutant allele. Digestion with EcoRI and Nhel and hybridization with a 912-bp probe (Xbal-Accl DNA fragment) labeled a 4,578bp EcoRI-digested DNA for the normal allele and 978-bp (EcoRINhel) and 3,600-bp (Nhel-EcoRI) DNAs for the C67X mutant allele. (c) RT-PCR analysis for the detection of WT and mutant Avp transcripts in the hypothalamus. A 366-bp cDNA spanning the $A(-1) T$ mutation was amplified using forward and reverse primers located within exon 1 and exon 2, respectively. Restriction digestion with Scal generated a 366-bp band from the normal allele and 265- and 101bp fragments from the mutant allele. DNA spanning the C67X mutation (267 bp) was amplified by the use of forward (exon 2) and reverse (exon 3 ) primers. Nhel digestion gave rise to 163 - and 104bp fragments derived from the mutant allele. lower viability than for cells expressing other types of mutations (36). The heterozygous C67X KI mice develop worsening DI with age and progressive, selective loss of AVP-producing neurons.

\section{Methods}

Gene targeting. AVP KI mice were generated by homologous recombination in R1 embryonic stem cells (41). Using a mouse AVP cDNA as a probe, $\lambda$ phage clones containing mouse $A v p$ and oxytocin $(O x t)$ genes were isolated from the $\lambda$ FIXII-129SvJ genomic library (Stratagene, La Jolla, California, USA). Targeting vectors for the $\mathrm{A}(-1) \mathrm{T}$ signal peptide mutation and the $\mathrm{C} 67 \mathrm{X}$ nonsense mutation were constructed using 7.6 - and $12.3-\mathrm{kb}$ genomic DNA fragments, respectively (Figure 1a). The $\mathrm{A}(-1) \mathrm{T}$ and $\mathrm{C} 67 \mathrm{X}$ mutations were introduced by overlapping PCR, creating ScaI and NheI restriction sites, respectively: codons TCC(S)/GCC(A) were changed to AGT(S) $\underline{A C T}(\mathrm{~T})$ and codons CGC(R)/TGC(C)/GCC(A) were changed to $\mathrm{CGC}(\mathrm{R}) / \underline{\mathrm{TAG}}(\mathrm{X}) / \underline{\mathrm{CCC}}$. For selection, a thymidine kinase cassette and a neomycin cassette flanked by loxP sites were introduced. The linearized targeting vector $(40 \mu \mathrm{g})$ was electroporated into approximately $8 \times 10^{6} \mathrm{R} 1$ embryonic stem cells (41), and cells were cultured in the presence of $300 \mu \mathrm{g} / \mathrm{ml} \mathrm{G} 418$ (Invitrogen Corp., Gaithersburg, Maryland, USA) and $2 \mu \mathrm{M}$ ganciclovir (Hoffman-La Roche Inc., Nutley, New Jersey, USA). Homologous recombination was confirmed by both Southern blot and PCR analyses. Seven of 17 clones positive for homologous recombination for the $\mathrm{A}(-1) \mathrm{T}$ mutation and 17 of more than 100 clones positive for the C67X mutation were then karyotyped to
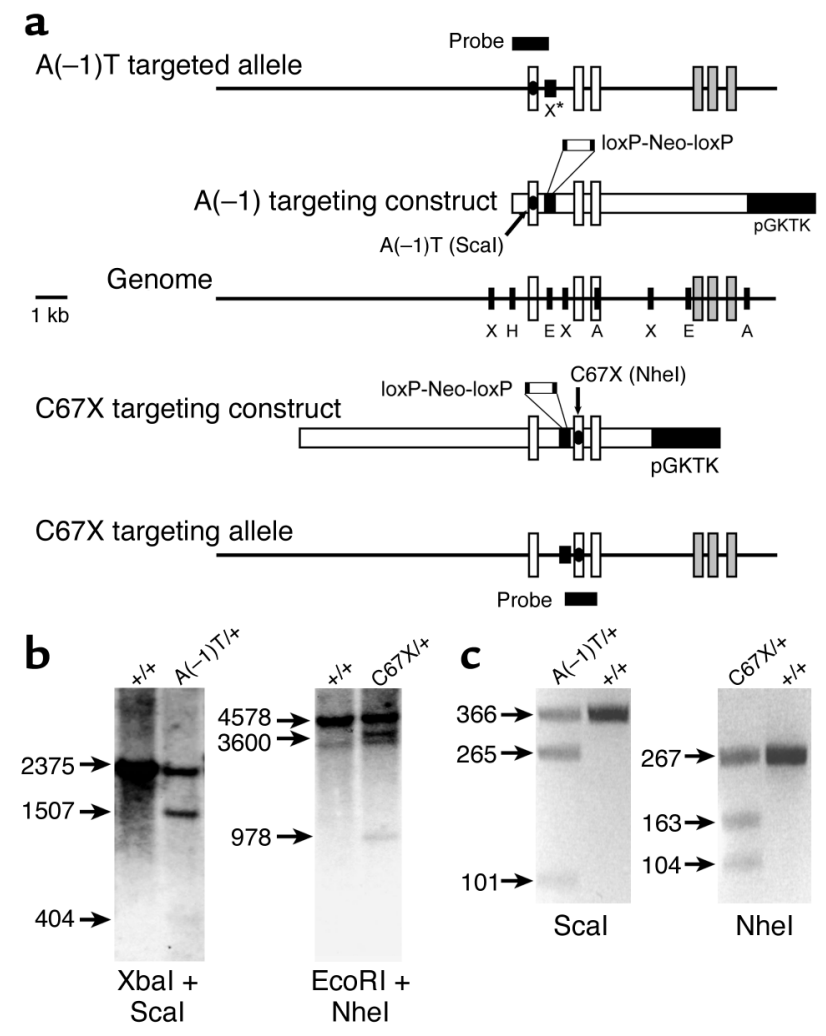
ensure normal chromosomal composition. Blastocyst injection was performed at the Children's Memorial Institute for Education and Research transgenic core (Chicago, Illinois, USA) using two embryonic stem cell clones for each of the mutations. All procedures involving animals were approved by the Northwestern University Animal Care and Use Committee.

Southern blot analysis. A HindIII-EcoRI DNA fragment (1,214 bp) spanning exon 1 of the mouse Avp gene and an XbaI-AccI fragment (912 bp) spanning exons 2 and 3 were used as probes for screening embryonic stem cells and the progeny of chimeric mice harboring the $\mathrm{A}(-1) \mathrm{T}$ and C67X mutations, respectively (Figure 1a). Total genomic DNA purified from tail fragments was digested with $\mathrm{XbaI}$ and $\mathrm{ScaI}$ for the $\mathrm{A}(-1) \mathrm{T}$ mutant, and with EcoRI and NheI for the C67X mutant. Digests were separated on a $0.8 \%$ agarose gel and transferred onto a Nytran membrane using the TurboBlotter rapid downward transfer system (Schleicher \& Schuell BioScience GmbH, Dassel, Germany). After UV crosslinking, the membrane was blocked and hybridized with ${ }^{32} \mathrm{P}-$-labeled probes in Rapid-hyb buffer (Amersham Biosciences, Buckinghamshire, England) according to the manufacturer's instructions. The blots were then washed three times and exposed to film.

$R N A$ preparation and RT-PCR. Mouse brains were dissected and frozen rapidly. Total RNA was extracted from the tissue block containing the hypothalamus using TRIzol reagent (Invitrogen Corp.) per the manufacturer's protocol. Extracted RNA was treated with DNase I (Promega Corp., Madison, Wisconsin, USA), reverse transcribed using AMV reverse transcriptase (Promega Corp.), and annealed to random hexamer primers. The RT reaction product was subjected to PCR amplification with Taq polymerase (Promega Corp.) in the presence of a trace amount of ${ }^{32} \mathrm{P}$-labeled dCTP using the following protocol: $94^{\circ} \mathrm{C}$ for $4 \mathrm{~min}$ utes; 37 cycles of 1 minute at $94^{\circ} \mathrm{C}, 1$ minute at $55^{\circ} \mathrm{C}$, and 1.5 minutes at $72^{\circ} \mathrm{C}$; and 10 minutes at $72^{\circ} \mathrm{C}$. Primers used to generate a DNA fragment spanning the mutation site were: $5^{\prime}$-ACAGTGCCCACCTATGCTCGCCAGGATGCT- $3^{\prime}$ and $5^{\prime}$-CGTCGCTGCAGCAGATGCCACGGCGG-3' for the A(-1)T mutation and $5^{\prime}$ TGGCGTTGCTTGGCTCCCGAGCGCGGGTGA- $3^{\prime}$ and $5^{\prime}$ GCGGCCCGGGCGGCAAAGGACGCTGCTTCG- $3^{\prime}$ for the C67X mutation. After electrophoresis on a $2 \%$ agarose gel, PCR products were cut out of the gel and DNA was extracted using the Gel Extraction Kit from Qiagen Inc. (Valencia, California, USA). The purified DNA was digested with ScaI for the A(-1)T mutation or NheI for the C67X mutation. The digested and undigested DNA was then run on an $8 \%$ polyacrylamide gel. After drying, the gel was exposed to a BAS-III imaging plate (Fuji Photo Film Co., Tokyo, Japan) and analyzed with a Storm 860 PhosphorImager and ImageQuant software (Amersham Biosciences).

Metabolic studies. Metabolic cages (Nalge Nunc International, Rochester, New York, USA) were used to collect urine from mice. Urine was collected for 24 hours following a habituation period of at least 24 hours. Water intake was measured by weighing the water bottles before and after this period. Urine volume was determined gravimetrically, after which it was stored at $-20^{\circ} \mathrm{C}$. Urine osmolality was measured with a microosmometer (model 3300; Advanced Instruments Inc., Norwood, Massachusetts, USA).

Serum AVP assay. Trunk blood was collected and serum was isolated by centrifugation for 15 minutes at $11,750 \mathrm{~g}$ at $4^{\circ} \mathrm{C}$. AVP was extracted from the serum using C18 Amprep Minicolumns (Amersham Biosciences) and assayed by ELISA per the manufacturer's instructions (Assay Designs Inc., Ann Arbor, Michigan, USA). Data were collected and analyzed with an Emax Microplate Reader and Softmax Pro 2.1 software (Molecular Devices Corp., Sunnyvale, California, USA).

Immunohistochemistry. Brains were fixed for 24 hours in $10 \%$ neutral buffered formalin at $4^{\circ} \mathrm{C}$. Paraffin embedding and sectioning (to $5 \mu \mathrm{m}$ thickness) was performed by the Pathology Core Facility at Northwestern Memorial Hospital (Chicago, Illinois, USA). Sections were deparaffinized and hydrated with xylenes and a graded series of alcohols, and then washed and permeabilized with TBS/0.025\% Tween-20 (Sigma-Aldrich, St. Louis, Missouri, USA). For costaining of NPII and oxytocin, endogenous peroxidase activity was blocked by incubation of slides in 3\% hydrogen peroxide/ methanol. Sections were blocked with $5 \%$ normal horse serum (Vector Laboratories Inc., Burlingame, California, USA) and incubated with a goat polyclonal antibody against mouse NPII $(1 \mu \mathrm{g} / \mathrm{ml}$, Santa Cruz Biotechnology Inc., Santa Cruz, California, USA) for 1 hour. Sections were then incubated with biotinylated horse anti-goat IgG $(6 \mu \mathrm{g} / \mathrm{ml}$, Vector Laboratories Inc.) and alkaline phosphatase-conjugated streptavidin (1:500 dilution, Vector Laboratories Inc.) for $10 \mathrm{~min}-$ utes each, followed by staining using the Alkaline Phosphatase Substrate Kit III (Vector Laboratories Inc.). After being washed with TBS/0.025\% Tween-20 and blocked with $5 \%$ normal goat serum, sections were incubated with rabbit polyclonal anti-OT (anti-oxytocin) antibody (Oncogene Research Products, San Diego, California) for 1 hour and with goat anti-rabbit IgG $(6 \mu \mathrm{g} / \mathrm{ml})$ and RTU Horseradish Peroxidase Streptavidin (both from Vector Laboratories Inc.) for 10 minutes each. Sections were stained with the DAB Substrate-Chromogen System (DAKO Corp., Carpinteria, California, USA). Neurons that were stained in the paraventricular nucleus (PVN) immediately dorsal to the suprachiasmatic nucleus were counted by a blinded observer using light microscopy at $\times 200$ magnification. Only those neurons having a clearly defined cell body and nucleus were counted. Cell counts were expressed as the ratio of the number of NPII-positive neurons to the number of OT-positive neurons.

For costaining of NPII with BiP (Grp78) or Chop (Gadd153), slides were blocked with normal donkey serum and coincubated with goat anti-NPII and either rabbit anti-Gadd153 (F-168, 1:20; Santa Cruz Biotech- 
nology Inc.) or rabbit anti-Grp78 (H-129, 1:20; Santa Cruz Biotechnology Inc.) for 2 hours at room temperature. After washing, slides were incubated with Cy3conjugated donkey anti-goat IgG and FITC-conjugated donkey anti-rabbit IgG (both 1:100; Jackson ImmunoResearch Laboratories, West Grove, Pennsylvania, USA) for 1 hour at room temperature.

For detection of caspase-3, slides were blocked with normal goat serum and incubated with rabbit anticleaved caspase-3 (9661S, 1:100; Westburg BV, Leusden, the Netherlands) for 1 hour at room temperature. After washing, slides were incubated with biotinylated antirabbit IgG. Detection was with RTU Horseradish Peroxidase Streptavidin and DAB as above. For detection of cathepsin D, slides were blocked with normal donkey serum and incubated with goat anti-cathepsin D (sc-6489, 1:100; Santa Cruz Biotechnology Inc.) for 1 hour at room temperature. After washing, slides were incubated with Cy3-conjugated donkey anti-goat IgG.

\section{Results}

Generation of Avp KI mice. Mice harboring mutations in the Avp gene were created by homologous recombination using standard techniques and the targeting constructs illustrated in Figure 1a. Chimeric males were bred to WT 129SvJ females and germline transmission was detected by PCR and restriction digestion (data not shown). Animals heterozygous for the mutation and containing the neomycin cassette flanked by loxP sites were bred to transgenic $129 \mathrm{SvJ}$ animals expressing Cre recombinase under the control of the cytomegalovirus promoter (42), and excision of the neomycin cassette was confirmed by PCR using primers flanking the one remaining loxP site (data not shown). For one of two founder lines for each mutation, correct targeting was confirmed by Southern blot analysis (Figure 1b). For the $\mathrm{A}(-1) \mathrm{T}$ mutation, the mutant allele introduced a new ScaI site and excision of the neomycin cassette introduced a new XbaI site, resulting in XbaI and ScaI restriction fragments of 1,507 and $404 \mathrm{bp}$, compared with 2,375 bp for the normal allele. The C67X mutant allele introduced a new NheI site, resulting in EcoRI and NheI restriction fragments of 978 and 3,600 bp DNA, whereas the normal allele produced a 4,578-bp fragment. Subsequent breeding yielded animals containing the mutations but lacking the Cre recombinase. These animals and their litter-matched controls were used in all subsequent studies.

Expression of the mutant Avp genes in the mouse hypothalamus. RT-PCR was performed to assess expression of the
Avp transcripts from normal and mutant alleles in the mouse hypothalamus (Figure 1c). RT-PCR yielded amplification products of 366 and $267 \mathrm{bp}$ for the $\mathrm{A}(-1) \mathrm{T}$ and C67X lines, respectively. The $\mathrm{A}(-1) \mathrm{T}$ and C67X normal and mutant alleles could be distinguished in heterozygotes by digesting the amplification products with ScaI and NheI, respectively. ScaI digestion of the PCR products from Av $p^{A(-1) T /+}$ mice produced a 366-bp band from the normal allele and 265and 101-bp bands from the mutant allele. NheI digestion of PCR products in Avp ${ }^{\mathrm{C} 67 X /+}$ mice yielded a $267-\mathrm{bp}$ WT band and 163-bp and 104-bp fragments from the mutant allele. The normal and mutant alleles were expressed at similar levels in both mouse lines.

Avp $667 X / C 67 X$ mice die soon after birth, whereas Avp ${ }^{A(-1) T / A(-1) T}$ mice are viable. The mutant mice were bred to homozygosity using standard heterozygote crosses. For the $\mathrm{A}(-1) \mathrm{T}$ mutation, progeny with the expected mendelian ratio of genotypes were obtained. In contrast, crosses of $A \nu p^{C 67 X /+}$ mice produced no homozygotes at weaning age (i.e., 3 weeks) from 12 litters. As an abnormal number of dead 2- to 4-day-old pups were observed in the cages with the live offspring from C67X heterozygote crosses, 1-day-old pups from 11 additional $A v p^{C 67 X /+}$ crosses were genotyped. These litters contained $17 \mathrm{WT}, 33$ heterozygote, and 15 homozygote pups, demonstrating that C67X homozygotes are born at the expected frequency but die soon after birth, likely from dehydration. These data are summarized in Table 1 and Table 2.

Avp $p^{\mathrm{C} 67 X /+}$ mice, but not $A v p^{A(-1) T /+}$ or $A \nu p^{A(-1) T / A(-1) T}$ mice, display altered water intake, urine output, and urine osmolality. Water intake, urine output, and urine osmolality of mutant mice and litter-matched WT controls were measured to determine whether these mutations caused altered water balance in mice similar to effects seen in humans. No significant differences were observed between homozygous $A v p^{A(-1) T / A(-1) T}$ mice, heterozygous $A v p^{A(-1) T /+}$ mice, and controls at 12 months of age (Figure 2). In the case of the C67X mutation, 6-month-old Avp ${ }^{C 67 X /+}$ mice consumed significantly more water over a 24-hour period than did WT Avp ${ }^{+/+}$controls (Figure 3a). Beginning at 1 month of age, heterozygous $A v p^{\mathrm{C} 67 X /+}$ mice also produced more urine over the course of 24 hours than did their litter-matched $A v \mathrm{p}^{+/+}$controls; this pathology became progressively worse with age (Figure 3b). Two-month-old Avp ${ }^{\mathrm{C} 67 \mathrm{X} /{ }^{+}}$mice produced four times as much urine as controls, and by age 6 months the difference was nearly tenfold. Conversely, urine osmolality was decreased in 2-month-old $A v p^{\mathrm{C} 67 \mathrm{X} /+}$ mice and

Table 1

Absolute and relative numbers of mice bearing the $A(-1) T$ allele

\begin{tabular}{|c|c|c|c|c|c|c|c|}
\hline \multirow[t]{2}{*}{ Parental genotypes } & \multirow[t]{2}{*}{ Age of pups } & \multirow[t]{2}{*}{ Litter size } & \multicolumn{3}{|c|}{ Genotypes of offspring } & \multicolumn{2}{|c|}{ Ratio of genotypes } \\
\hline & & & $\mathrm{A}(-1) \mathrm{T} / \mathrm{A}(-1) \mathrm{T}$ & $A(-1) T /+$ & $+/+$ & Actual & Expected \\
\hline $\mathrm{A}(-1) \mathrm{T} /+\times \mathrm{A}(-1) \mathrm{T} /+$ & $3 w k$ & $5.5 \pm 3$ & 36 & 58 & 32 & $\sim 1: 2: 1$ & $1: 2: 1$ \\
\hline
\end{tabular}

Data are mean \pm SEM. 
Table 2

Absolute and relative numbers of mice bearing the C67X allele

\begin{tabular}{|c|c|c|c|c|c|c|c|}
\hline \multirow[t]{2}{*}{ Parental genotypes } & \multirow[t]{2}{*}{ Age of pups } & \multirow[t]{2}{*}{ Litter sizes } & \multicolumn{3}{|c|}{ Genotypes of offspring } & \multicolumn{2}{|c|}{ Ratio of genotypes } \\
\hline & & & C67X/C67X & $\mathrm{C} 67 \mathrm{X} /+$ & $+/+$ & Actual & Expected \\
\hline $\mathrm{C} 67 \mathrm{X} /+\times \mathrm{C} 67 \mathrm{X} /+$ & $1 d$ & $6 \pm 3$ & 15 & 33 & 17 & $\sim 1: 2: 1$ & $1: 2: 1$ \\
\hline $\mathrm{C} 67 \mathrm{X} /+\times \mathrm{C} 67 \mathrm{X} /+$ & $3 w k$ & $3.5 \pm 1$ & 0 & 27 & 15 & $\sim 0: 2: 1$ & $1: 2: 1$ \\
\hline $\mathrm{C} 67 \mathrm{X} /+\mathrm{x}+/+$ & $3 w k$ & $5 \pm 2$ & $\mathrm{~N} / \mathrm{A}$ & 117 & 107 & $\sim 1: 1$ & $1: 1$ \\
\hline
\end{tabular}

Data are mean \pm SEM. N/A, not applicable.

6-month-old Avp ${ }^{\mathrm{C} 67 X /+}$ mice compared with controls (Figure 3c). Thus, like humans with FNDI, $A v p^{\mathrm{C} 67 X /+}$ mice produce excessive amounts of dilute urine but compensate by increasing water intake.

Avp ${ }^{\mathrm{C} 67 \mathrm{X} /{ }^{+}}$mice exbibit decreased serum AVP concentrations. Serum AVP concentrations were measured at various ages using a specific ELISA to determine whether the metabolic abnormalities seen in the Avp ${ }^{\mathrm{C} 67 \mathrm{X} /+}$ mice could be caused by a reduction in circulating AVP. Three-, 6-, 9-, and 12-month-old $A v p^{C 67 X /+}$ mice had lower serum AVP concentrations than did their WT littermates (Figure 4a). Serum AVP concentrations were also measured in 1-month-old mice after a 24-hour period of water deprivation to study the changes in AVP secretion in response to this strong stimulus for AVP secretion. Following water deprivation, the concentration of serum AVP in Avp 6 C67X/+ mice was only $20 \%$ of the level in $A v p^{+/+}$ mice (Figure 4b).

Immunohistochemical detection of vasopressinergic neurons in the bypothalamus. Immunohistochemical analysis was performed to determine whether there was loss of AVP neurons in the Avp ${ }^{\mathrm{C} 67 \mathrm{X} /+}$ mice. Hypothalami of 1-, 2-, 6-, and 18-month-old WT and mutant mice were immunostained with polyclonal antibodies against NPII and OT. There was no significant difference between the two groups in the numbers of oxytocinergic neurons in the PVN (Figure 5a, brown stain). In contrast, $A v p^{\mathrm{C} 67 \mathrm{X} /+}$ mice exhibited fewer vasopressinergic neurons than $A \nu \mathrm{p}^{+/+}$mice beginning at 2 months of age, with a near-total loss of AVP-expressing neurons by 18 months (Figure 5a, blue stain). Neurons were counted and expressed as a ratio of vasopressinergic to oxytocinergic neurons as a way to normalize between sections. The ratio of vasopressinergic neurons to oxytocinergic neurons in $A v p^{C 67 X /+}$ mice was statistically lower than in $A v p^{+/+}$mice at 2, 6, and 18 months of age (PVN, Figure 5b). A similar progressive loss of vasopressinergic neurons was seen in the supraoptic nucleus (Figure 5b).

In the PVN of $A v p^{+/+}$mice, both the cell bodies and a dense network of neuronal projections stained for NPII (Figure 5a). In contrast, staining of the projections was diminished in the $A v p^{\mathrm{C} 67 X /+}$ mice at all ages studied (compare upper and lower panels in Figure 5a). Figure 6 illustrates the entire tract from the PVN to the supraoptic nucleus in young mice. Note that NPII immunostaining in the neuronal projections seen in the $A v p^{+/+}$mice is nearly absent in the $A v \mathrm{C}^{\mathrm{C} 67 \mathrm{X} /+}$ mice at
1 month after birth, preceding the overt loss of vasopressinergic neuronal cell bodies.

ER stress-associated protein expression in vasopressinergic neurons. Levels of the molecular chaperone BiP (Grp78) and an ER stress-induced transcription factor, Chop (Gadd153), were measured in the PVN by immunohistochemistry. Chop was not detected in either $A v p^{+/+}$or $A v p^{\mathrm{C} 67 \mathrm{X} /+}$ mice (Figure 7a). BiP was also absent in $A v p^{+/+}$ mice, but was strongly induced in $A \nu p^{\mathrm{C} 67 \mathrm{X} /+}$ mice (Figure $7 \mathrm{~b}$ ). Costaining for NPII confirms that BiP-expressing cells are vasopressinergic.

\section{Discussion}

In this study, we generated a murine model of FNDI that faithfully replicates several features of the human
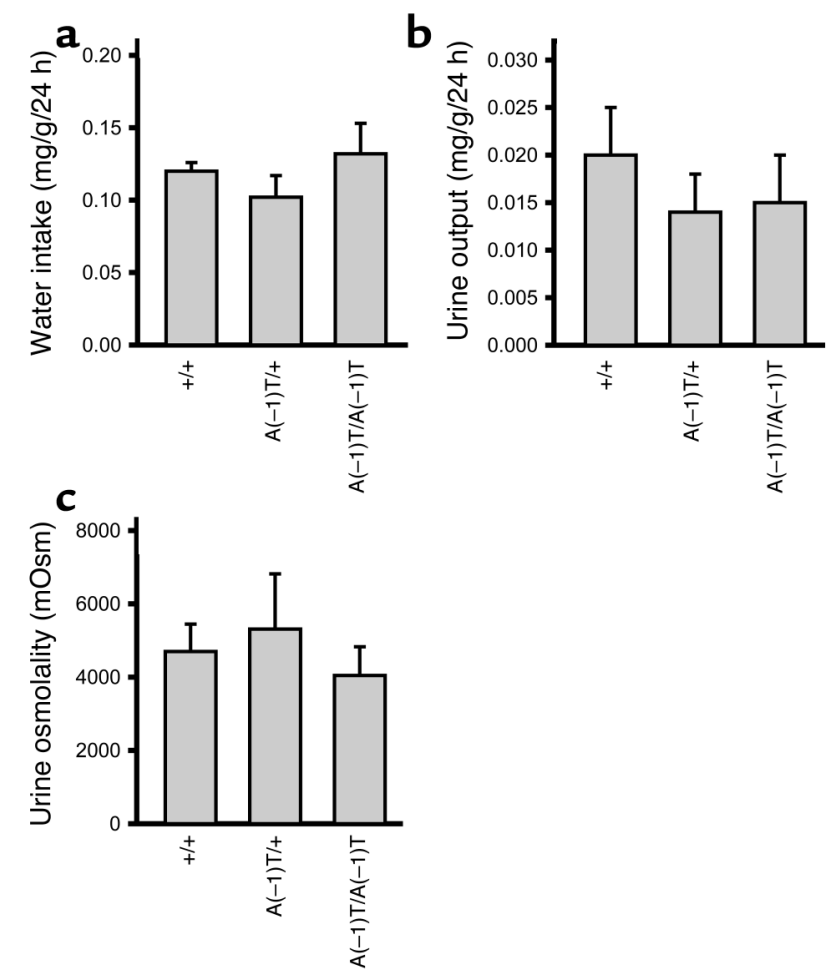

Figure 2

Osmoregulation in mice carrying the $\mathrm{A}(-1) \mathrm{T}$ mutation. No significant differences were observed between 12-month-old Avp ${ }^{A(-1) T / A(-1) T}$ mice, $A v p^{A(-1) T /+}$ mice, and their WT littermates with regard to (a) water intake over a 24-hour period; (b) urine output over a 24hour period; or (c) urine osmolality ( $n=4$ for all groups). Data are mean \pm SEM. mOsm, milliosmoles. 
a

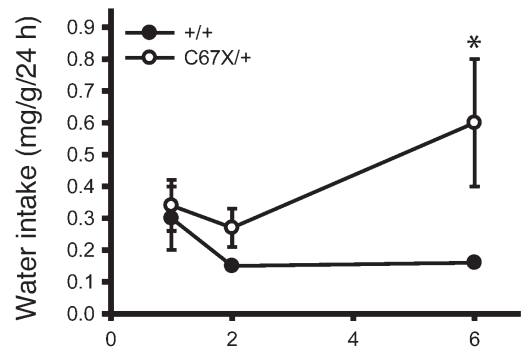

b

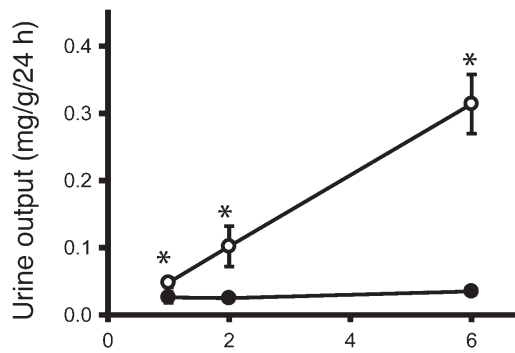

c

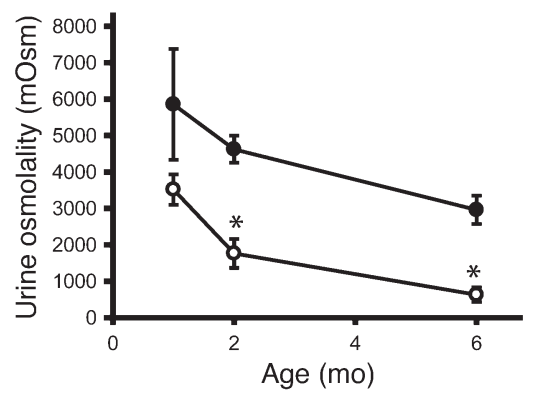

disorder, including autosomal dominant transmission, delayed onset and progressive worsening of the defect in water retention, and loss of AVP-producing neurons in the hypothalamus.

The delayed onset of FNDI has led several groups to speculate that the mutant AVP precursor causes cellular toxicity, leading to eventual loss of AVP-producing neurons (reviewed in ref. 35). This hypothesis is supported by in vitro studies showing accumulation of mutant vasopressin precursors in transfected cell lines $(36-38,40,43)$ and cytotoxicity of certain mutants (36). Of note, there is little evidence of apoptosis, suggesting that cell death may occur via other pathways (36).

The processing of mutant vasopressin has also been examined using metabolic labeling studies $(37,38,40$, 43). These experiments document persistent endogly-
Figure 3

Osmoregulation in mice with the C67X mutation. (a) Water intake of mice over a 24-hour period. Six-month-old Avp ${ }^{\mathrm{C} 67 X /+}$ mice drank significantly more water than did their WT littermates. (b) Urine output of mice over a 24-hour period. One-, 2-, and 6-month-old Avp ${ }^{\mathrm{C} 67 \mathrm{X} /+}$ mice excreted significantly more urine than did their WT littermates. (c) Urine osmolality. Urine samples from $A v p^{C 67 X /+}$ mice at 2 and 6 months of age were more dilute than those of their WT littermates. $n \geq 5$ for all groups. Data are mean \pm SEM. ${ }^{*} P<0.05$.

cosidase $\mathrm{H}$ sensitivity, consistent with prohormone retention in the ER. The ER becomes distended (43), and immunoreactive protein forms perinuclear punctate complexes rather than diffuse cytoplasmic staining (36). Coexpression of WT and mutant AVP precursors results in the formation of WT/mutant dimers, and the mutant prohormone delays WT protein processing (40). Thus, it appears that the mutant vasopressin precursor may exert at least two distinct cellular effects: (a) formation of complexes with the WT precursor protein that impair its processing, and (b) accumulation of misfolded proteins in the ER, causing cellular toxicity by mechanisms that remain to be fully characterized. Because these in vitro experiments involve high-level expression of the mutant protein and occur in dividing cell lines, it is desirable to develop models that more closely mimic conditions in vivo.

Two animal models have been used previously to study central DI. In the Brattleboro rat, a naturally occurring single base deletion in the NPII coding sequence produces AVP precursors with continued translation into the mRNA poly-A tail, leading to a polylysine stretch of amino acids. In these animals, DI is transmitted in an autosomal recessive manner (44), suggesting that it is caused by an absolute deficiency of AVP. Although mutant precursors are retained within the ER, there is no apparent loss of AVP-producing neurons (45). The absence of cell death in the Brattleboro rat might be explained by differences in the effects of various mutant proteins or by species differences in the cellular mechanisms for coping with mutant AVP precursors.

Of interest, the same mutant described here (C67X) has been expressed in transgenic rats $(46,47)$. In this case, features of DI were manifest only as a small increase in water intake after repeated dehydration (46). However, there was evidence of retention of mutant precursors
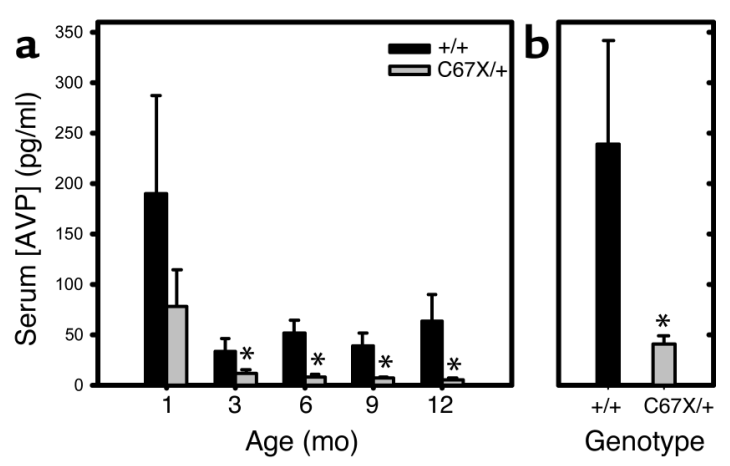

\section{Figure 4}

Serum AVP analysis. (a) Serum AVP levels of $A v p^{\mathrm{C} 67 X /+}$ and $A v p^{+/+}$mice at five different ages were quantified using ELISA. At 3, 6, 9, and 12 months of age, serum from $A v p^{\mathrm{C} 67 X /+}$ mice contained significantly less immunoreactive AVP than did serum from the WT mice ( $n \geq 4$ for all groups). (b) Serum immunoreactive AVP concentrations from 1-month-old $A v p^{\mathrm{C} 67 X /+}$ and WT mice following a 24-hour period of water deprivation. Values for $A v p^{\mathrm{C} 67 X /+}$ samples were significantly lower than those for WT samples. Data are mean \pm SEM. ${ }^{*} P<0.05$. 
a
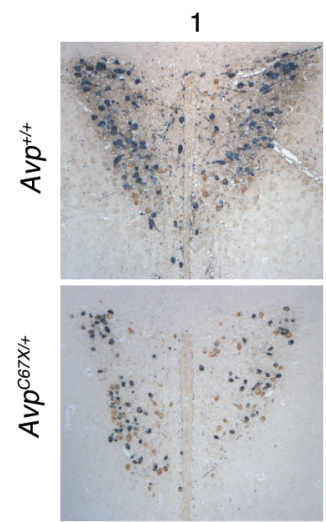

b

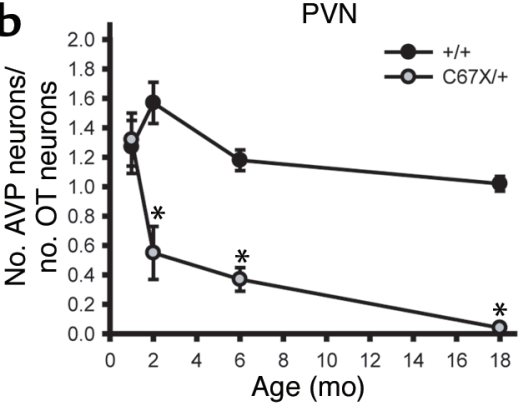

PVN
Age (mo)

6
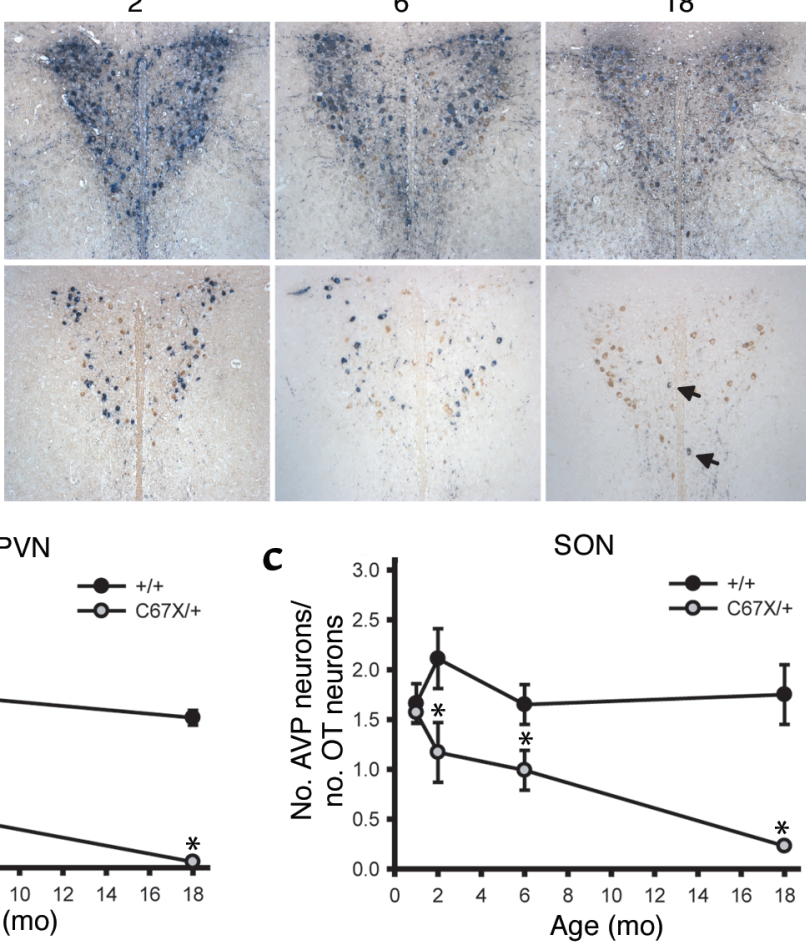

Figure 5

Number of vasopressinergic neurons in the $\mathrm{PVN}$ and supraoptic nuclei (SON) of the hypothalamus decrease with age in $\mathrm{Avp}^{\mathrm{C} 67 \mathrm{X} /+}$ mice. (a) Representative hypothalamic sections from the PVN of 1-, 2-, 6-, and 18month-old $A v p^{\mathrm{C} 67 X /+}$ mice (bottom row) and their WT littermates (top row) immunostained for NPII (blue, alkaline phosphatase) and OT (brown, DAB) are shown. Although the PVN of 1-month-old Avp ${ }^{\mathrm{C} 67 \mathrm{X} /+}$ mice and WT mice contained approximately equal numbers of vasopressinergic cell bodies (left panels), the PVN of the 18-month-old Avp ${ }^{\text {C67X/+ }}$ mouse appears to have only two AVP-producing neurons (arrows, lower right panel). The number of oxytocinergic neurons is unchanged across all ages and genetic variations. Magnification, $\times 200$. (b and c) Ratios of the numbers of magnocellular vasopressinergic neurons to oxytocinergic neurons in the PVN (b) and supraoptic nucleus (SON) (c). Sections from 2-, 6-, and 18-month-old Avp ${ }^{\mathrm{C} 67 \mathrm{X} /+}$ mice showed significantly lower ratios than their littermates ( $n=6$ animals for each group; three sections were counted for each animal). Data are mean \pm SEM. ${ }^{*} P<0.05$. in distended ER. In addition, vesicles contained markers of the lysosomal degradation pathway, suggesting autophagy (47). There was no evidence of cell death in the transgenic rats. Because the same mutant was expressed in this transgenic model and in our KI mice, it is interesting that the mice exhibit features more typical of the human disorder. Although this may be due to species differences between rats and mice, differences in gene dosage also provide a plausible explanation. The transgenic rats retain two normal vasopressin alleles in addition to the transgenic mutant gene, whereas the KI mice possess one normal vasopressin allele and one mutant allele, analogous to the human condition. Our RT-PCR studies document similar expression levels of the WT and mutant alleles, consistent with the fact that AVP expression is driven by the endogenous gene, which remains in its normal chromosomal locus. In view of evidence for interaction of WT and mutant precursor pro-

\section{Figure 6}

Intracellular localization of the Avp gene products immunoreactive for NPII. In WT animals at both 1 and 2 months of age, immunoreactive NPII (blue, alkaline phosphatase) was present in the neural projections between the hypothalamic PVN and supraoptic nucleus (upper panels). In contrast, staining of immunoreactive NPII is confined to the cell bodies of the 1- and 2-month-old $A v p^{\mathrm{C} 67 X /+}$ mice (lower panels). Arrows in the inset image in the upper left panel highlight the neural projections in 1-month old animals; the inset in the lower left panel shows an absence of staining outside the cell bodies. This is further illustrated in the insets in the right panels, which contain confocal micrographs from 2-month-old animals. Magnification, $\times 100$; insets, $\times 400$. teins during processing (40), gene dosage could affect the ratio of mutant-WT complexes. There may also be differences in the physiologic stimuli for vasopressin expression. For example, chronic mild dehydration in the mice would lead to upregulation of vasopressin gene expression, $50 \%$ of which is comprised of mutant precursors. Based on in vitro metabolic studies, processing of the mutant precursor is delayed relative to processing of the WT protein (36). Thus, a relative excess of mutant protein is predicted to accumulate over time.

The phenotypes of the mice with two different FNDI mutations were distinct. In the case of the signal sequence $\mathrm{A}(-1) \mathrm{T}$ KI mutant, there was no apparent DI

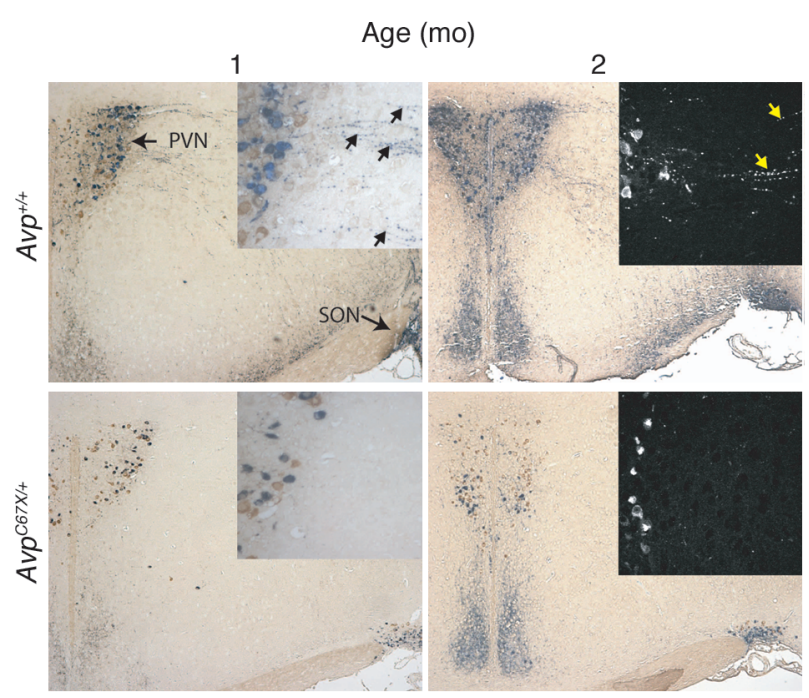


a
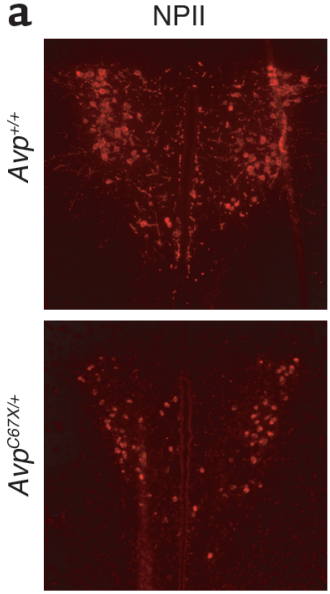

b
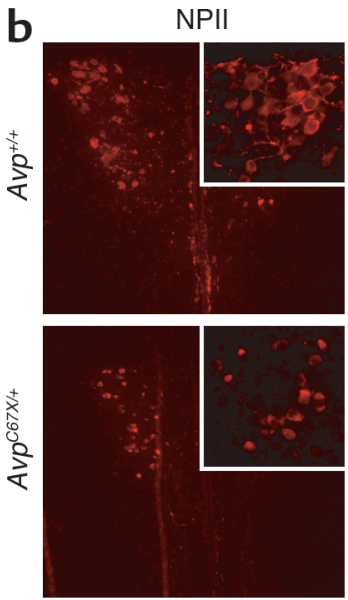
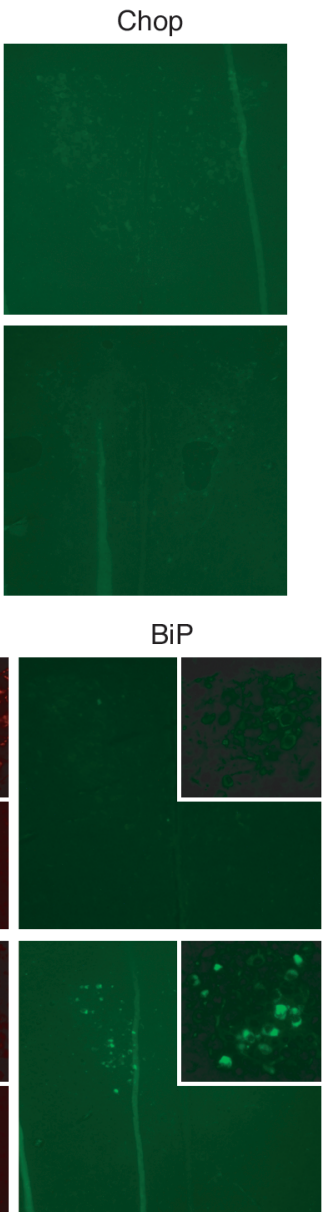

Merge

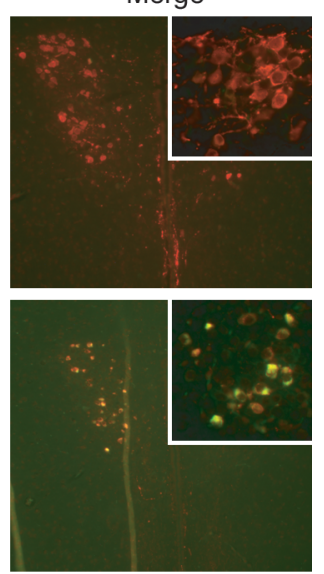

\section{Figure 7}

Immunochemical detection of BiP and Chop. Brains were removed from 6-weekold Avp ${ }^{\mathrm{C} 67 \mathrm{X} /+}$ mice and WT littermates. Sections through the PVN were identified and costained for NPII and either Chop (a) or BiP (b). For BiP, the BiP and NPII images were also merged and demonstrate that BiP expression in $A v p^{C 67 X /+}$ mice is restricted to vasopressinergic neurons.

phenotype and we did not detect loss of AVP-producing neurons, even in homozygous mice. This mutation gives rise to aberrant preproAVP that is glycosylated but retains the signal peptide as a result of inefficient cleavage. Consistent with the in vivo results, cell lines expressing the $\mathrm{A}(-1) \mathrm{T}$ mutant were more viable than cells expressing the $\mathrm{C} 67 \mathrm{X}$ mutant (36). In contrast with the $\mathrm{A}(-1) \mathrm{T}$ mutant, a severe and consistent phenotype was seen in mice carrying the C67X mutation. The more severe phenotype in the C67X mutant is consistent with in vitro studies that show it is the most cytotoxic among several AVP mutants studied (36). The C67X mutation was lethal in the homozygous state, presumably due to a complete lack of functional AVP. Heterozygotes were more informative, however. Water intake and urine volumes were increased concomitant with decreased urine osmolality and serum AVP. By 6 months of age, the 24hour urine volume of the C67X mice was about onethird of their body weight. This is not dissimilar from affected children, who may produce several liters of urine each day and must be provided with easy access to

fluids to avoid severe dehydration. Like humans, the mice are able to compensate for profound diuresis by drinking copious amounts of water, indicating that their thirst mechanism remains intact.

One of the advantages of developing an animal model of FNDI is the ability to correlate the phenotype with pathological changes in the brain regions that produce AVP. In C67X heterozygotes, the number of AVP-expressing neurons in the PVN of the hypothalamus decreased beginning at 2 months of age. Comparison with OTproducing cells demonstrated that the neuronal cell loss was specific for AVP-producing neurons. The progressive loss of AVP-producing neurons correlated with the worsening features of DI, suggesting gradual cell loss over time.

Apoptosis was not detected using a TUNEL assay or immunohistochemical analyses of apoptosis markers (caspase-3, cathepsin D; data not shown). However, given the small number of vasopressinproducing neurons and the progressive loss of cells over weeks to months, these assays are unlikely to be sensitive enough to detect apoptosis of a small number of neurons. There was no apparent induction of the ER stress protein Chop (48), which has been reported to be proapoptotic (49, 50). In contrast, there was marked induction of BiP, a member of the HSP70 family of molecular chaperones. BiP binds avidly to misfolded proteins whose transport from the ER is blocked, and BiP expression is increased as part of the "unfolded protein response" (reviewed in ref. 51). Thus, elevated levels of BiP are consistent with the retention of mutant AVP precursors in the ER of C67X mice. It is notable that NPII immunoreactivity was confined to the cell bodies of magnocellular neurons. The absence of staining in the neuronal projections suggests that AVP precursors produced from the normal allele may also be retained within the ER through interaction with mutant precursors (40). Thus, the vasopressinergic neurons of C67X mice exhibit ER accumulation of vasopressin precursors and induction of the $\mathrm{BiP}$ chaperone response. These neurons are selectively lost over several months, presumably the consequence of toxic effects of the mutant proteins. However, the ultimate steps that lead to cell loss remain unknown.

We propose that FNDI can be added to a list of neurodegenerative disorders that includes Alzheimer disease, Parkinson disease, and various CAG-repeat diseases (52-54). In the case of FNDI, the combination of in vitro and in vivo models suggests cellular dysfunction by several different mechanisms, including dominant 
negative activity by interactions of mutant and WT precursors, accumulation of mutant precursors in the ER leading to stress protein responses and autophagy, and cellular toxicity by pathways that remain incompletely defined. Ultimately, the loss of AVP-producing neurons depletes AVP production below a level where compensatory responses can prevent DI. Because the C67X KI mouse faithfully replicates many features of FNDI, it provides a useful model for studying the specific molecular and cellular mechanisms responsible for the pathology seen in FNDI, with potential implications for other neurodegenerative diseases.

\section{Acknowledgments}

We are grateful to S.A. Camper for invaluable instruction in embryonic stem cell techniques and gene targeting; A. Nagy, R. Nagy, and W. Abramow-Newerly for providing R1 embryonic stem cells; K. Foley and R. Eisenman for providing the CMV-Cre transgenic mice; Gary L. Robertson, J.J. Meeks, and E.J. Lee for helpful discussions; and A. Cumpton, T. Kotlar, L. Sabacan, and K. Stanfield for technical assistance.

1. Baylis, P.H., and Robertson, G.L. 1981. Vasopressin function in familial cranial diabetes insipidus. Postgrad. Med. J. 57:36-40.

2. Braverman, L.E., Mancini, J.P., and McGoldrick, D.M. 1965. Hereditary idiopathic diabetes insipidus: a case report with autopsy findings. Ann. Intern. Med. 63:503-508.

3. Green, J.R., Buchan, G.C., Alvord, E.C., and Swanson, A.G. 1967. Hereditary and idiopathic types of diabetes insipidus. Brain. 90:707-714.

4. Nagai, I., Li, C.H., Hsieh, S.M., Kizaki, T., and Urano, Y. 1984. Two cases of hereditary diabetes insipidus, with an autopsy finding in one. Acta Endocrinol. 105:318-323.

5. Bergeron, C., Kovacs, K., Ezrin, C., and Mizzen, C. 1991. Hereditary diabetes insipidus: an immunohistochemical study of the hypothalamus and pituitary gland. Acta Neuropathol. (Berl.) 81:345-348.

6. Brownstein, M.J., Russel, J.T., and Gainer, H. 1980. Synthesis, transport, and release of posterior pituitary hormones. Science. 207:373-378.

7. Sausville, E., Carney, D., and Battey, J. 1985. The human vasopressin gene is linked to the oxytocin gene and is selectively expressed in a cultured lung cancer cell line. J. Biol. Chem. 260:10236-10241.

8. Ito, M., Mori, Y., Oiso, Y., and Saito, H. 1991. A single base substitution in the coding region for neurophysin II associated with familial central diabetes insipidus. J. Clin. Invest. 87:725-728.

9. Bahnsen, U., et al. 1992. A missense mutation in the vasopressin-neurophysin precursor gene cosegregates with human autosomal dominant neurohypophyseal diabetes insipidus. EMBO J. 11:19-23.

10. Ito, M., et al. 1993. Possible involvement of inefficient cleavage of preprovasopressin by signal peptidase as a cause for familial central diabetes insipidus. J. Clin. Invest. 91:2565-2571.

11. Yuasa, H., et al. 1993. Glu-47, which forms a salt bridge between neurophysin-II and arginine vasopressin, is deleted in patients with familial central diabetes insipidus. J. Clin. Endocrinol. Metab. 77:600-604.

12. Krishnamani, M.R., Phillips, J.A.I., and Copeland, K.C. 1993. Detection of a novel arginine vasopressin defect by dideoxy fingerprinting. J. Clin. Endocrinol. Metab. 77:596-598.

13. McLeod, J.F., et al. 1993. Familial neurohypophyseal diabetes insipidus associated with a signal peptide mutation. J. Clin. Endocrinol. Metab. 77:599A-599G.

14. Repaske, D.R., and Browning, J.E. 1994. A de novo mutation in the coding sequence for neurophysin-II (Pro24-->Leu) is associated with onset and transmission of autosomal dominant neurohypophyseal diabetes insipidus. J. Clin. Endocrinol. Metab. 79:421-427.

15. Nagasaki, H., et al. 1995. Two novel mutations in the coding region for neurophysin-II associated with familial central diabetes insipidus. J. Clin. Endocrinol. Metab. 80:1352-1356.

16. Rauch, F., Lenzner, C., Nurnberg, P., Frommel, C., and Vetter, U. 1996. A novel mutation in the coding region for neurophysin-II is associated with autosomal dominant neurohypophyseal diabetes insipidus. Clin. Endocrinol. (Oxf.) 44:45-51.

17. Rittig, S., et al. 1996. Identification of 13 new mutations in the vasopressin-neurophysin II gene in 17 kindreds with familial autosomal dominant neurohypophyseal diabetes insipidus. Am. J. Hum. Genet. 58:107-117.
18. Rutishauser, J., et al. 1996. A novel point mutation in the translation initiation codon of the pre-pro-vasopressin-neurophysin II gene: cosegregation with morphological abnormalities and clinical symptoms in autosomal dominant neurohypophyseal diabetes insipidus. J. Clin. Endocrinol. Metab. 81:192-198.

19. Ueta, Y., et al. 1996. A new type of familial central diabetes insipidus caused by a single base substitution in the neurophysin II coding region of the vasopressin gene. J. Clin. Endocrinol. Metab. 81:1787-1790.

20. Gagliardi, P.C., Bernasconi, S., and Repaske, D.R. 1997. Autosomal dominant neurohypophyseal diabetes insipidus associated with a missense mutation encoding Gly23-->Val in neurophysin II. J. Clin. Endocrinol. Metab. 82:3643-3646.

21. Grant, F.D., Ahmadi, A., Hosley, C.M., and Majzoub, J.A. 1998. Two novel mutations of the vasopressin gene associated with familial diabetes insipidus and identification of an asymptomatic carrier infant. J. Clin. Endocrinol. Metab. 83:3958-3964.

22. Heppner, C., Kotzka, J., Bullmann, C., Krone, W., and Muller-Wieland, D. 1998. Identification of mutations of the arginine vasopressin-neurophysin II gene in two kindreds with familial central diabetes insipidus. J. Clin. Endocrinol. Metab. 83:693-696.

23. Calvo, B., et al. 1998. Identification of a novel nonsense mutation and a missense substitution in the vasopressin-neurophysin II gene in two Spanish kindreds with familial neurohypophyseal diabetes insipidus. J. Clin. Endocrinol. Metab. 83:995-997.

24. Kawakami, A., et al. 1998. Central diabetes insipidus associated with a missense mutation in the arginine vasopressin gene that replaces Ala at the carboxyterminus of the signal peptide with Thr. Intern. Med. 37:683-686.

25. Rutishauser, J., Kopp, P., Gaskill, M.B., Kotlar, T.J., and Robertson, G.L. 1999. A novel mutation (R97C) in the neurophysin moiety of preprovasopressin-neurophysin II associated with autosomal-dominant neurohypophyseal diabetes insipidus. Mol. Genet. Metab. 67:89-92.

26. Fujii, H., Iida, S., and Moriwaki, K. 2000. Familial neurohypophyseal diabetes insipidus associated with a novel mutation in the vasopressin-neurophysin II gene. Int. J. Mol. Med. 5:229-234.

27. Abbes, A.P., et al. 2000. Identification of two distinct mutations at the same nucleotide position, concomitantly with a novel polymorphism in the vasopressin- neurophysin II gene (AVP-NP II) in two dutch families with familial neurohypophyseal diabetes insipidus. Clin. Chem. 46:1699-1702.

28. Skordis, N., et al. 2000. A novel arginine vasopressin-neurophysin II mutation causes autosomal dominant neurohypophyseal diabetes insipidus and morphologic pituitary changes. Horm. Res. 53:239-245.

29. Fluck, C.E., et al. 2001. Autosomal dominant neurohypophyseal diabetes insipidus in a Swiss family, caused by a novel mutation (C59Delta/A60W) in the neurophysin moiety of prepro-vasopressinneurophysin II (AVP-NP II). Eur. J. Endocrinol. 145:439-444.

30. DiMeglio, L.A., Gagliardi, P.C., Browning, J.E., Quigley, C.A., and Repaske, D.R. 2001. A missense mutation encoding cys(67) --> gly in neurophysin II is associated with early onset autosomal dominant neurohypophyseal diabetes insipidus. Mol. Genet. Metab. 72:39-44.

31. Bullmann, C., et al. 2002. Identification of a novel mutation in the arginine vasopressin-neurophysin II gene in familial central diabetes insipidus. Exp. Clin. Endocrinol. Diabetes. 110:134-137.

32. Rutishauser, J., Kopp, P., Gaskill, M.B., Kotlar, T.J., and Robertson, G.L. 2002. Clinical and molecular analysis of three families with autosomal dominant neurohypophyseal diabetes insipidus associated with a novel and recurrent mutations in the vasopressin-neurophysin II gene. Eur. J. Endocrinol. 146:649-656.

33. Santiprabhob, J., Browning, J., and Repaske, D. 2002. A missense mutation encoding Cys73Phe in neurophysin II is associated with autosomal dominant neurohypophyseal diabetes insipidus. Mol. Genet. Metab. 77:112-118.

34. Mahoney, C.P., Weinberger, E., Bryant, C., Ito, M., and Jameson, J.L. 2002. Effects of aging on vasopressin production in a kindred with autosomal dominant neurohypophyseal diabetes insipidus due to the DeltaE47 neurophysin mutation. J. Clin. Endocrinol. Metab. 87:870-876.

35. Hansen, L.K., Rittig, S., and Robertson, G.L. 1997. Genetic basis of familial neurohypophyseal diabetes insipidus. Trends Endocrinol. Metab. 8:363-372.

36. Ito, M., Jameson, J.L., and Ito, M. 1997. Molecular basis of autosomal dominant neurohypophyseal diabetes insipidus. Cellular toxicity caused by the accumulation of mutant vasopressin precursors within the endoplasmic reticulum. J. Clin. Invest. 99:1897-1905.

37. Siggaard, C., et al. 1999. Clinical and molecular evidence of abnormal processing and trafficking of the vasopressin preprohormone in a large kindred with familial neurohypophyseal diabetes insipidus due to a signal peptide mutation. J. Clin. Endocrinol. Metab. 84:2933-2941.

38. Nijenhuis, M., Zalm, R., and Burbach, J.P. 1999. Mutations in the vasopressin prohormone involved in diabetes insipidus impair endoplasmic reticulum export but not sorting. J. Biol. Chem. 274:21200-21208.

39. Beuret, N., Rutishauser, J., Bider, M.D., and Spiess, M. 1999. Mechanism 
of endoplasmic reticulum retention of mutant vasopressin precursor caused by a signal peptide truncation associated with diabetes insipidus. J. Biol. Chem. 274:18965-18972.

40. Ito, M., Yu, R.N., and Jameson, J.L. 1999. Mutant vasopressin precursors that cause autosomal dominant neurohypophyseal diabetes insipidus retain dimerization and impair the secretion of wild-type proteins. J. Biol. Chem. 274:9029-9037.

41. Nagy, A., Rossant, J., Nagy, R., Abramow-Newerly, W., and Roder, J.C. 1993. Derivation of completely cell culture-derived mice from early-passage embryonic stem cells. Proc. Natl. Acad. Sci. U. S. A. 90:8424-8428.

42. Rossant, J., and Nagy, A. 1995. Genome engineering: the new mouse genetics. Nat. Med. 1:592-594.

43. Nijenhuis, M., et al. 2001. Familial neurohypophysial diabetes insipidus in a large Dutch kindred: effect of the onset of diabetes on growth in children and cell biological defects of the mutant vasopressin prohormone. J. Clin. Endocrinol. Metab. 86:3410-3420.

44. Schmale, H., and Richter, D. 1984. Single base deletion in the vasopressin gene is the cause of diabetes insipidus in Brattleboro rats. Nature. 308:705-709.

45. Valtin, H. 1977. Genetic models for hypothalamic and nephrogenic diabetes insipidus. In Disturbances in body fluid osmolality. American Physiological Society. Bethesda, Maryland, USA. 197-215.

46. Si-Hoe, S.L., et al. 2000. Endoplasmic reticulum derangement in hypothalamic neurons of rats expressing a familial neurohypophyseal dia- betes insipidus mutant vasopressin transgene. FASEB J. 14:1680-1684. 47. Davies, J., and Murphy, D. 2002. Autophagy in hypothalamic neurones of rats expressing a familial neurohypophysial diabetes insipidus transgene. J. Neuroendocrinol. 14:629-637.

48. Wang, X.Z., et al. 1996. Signals from the stressed endoplasmic reticulum induce C/EBP-homologous protein (CHOP/GADD153). Mol. Cell. Biol. 16:4273-4280.

49. Matsumoto, M., Minami, M., Takeda, K., Sakao, Y., and Akira, S. 1996 Ectopic expression of CHOP (GADD153) induces apoptosis in M1 myeloblastic leukemia cells. FEBS Lett. 395:143-147.

50. McCullough, K.D., Martindale, J.L., Klotz, L.O., Aw, T.Y., and Holbrook, N.J. 2001. Gadd153 sensitizes cells to endoplasmic reticulum stress by down-regulating $\mathrm{Bcl} 2$ and perturbing the cellular redox state. Mol. Cell. Biol. 21:1249-1259.

51. Gething, M.J. 1999. Role and regulation of the ER chaperone BiP. Semin. Cell Dev. Biol. 10:465-472.

52. Wong, P.C., Cai, H., Borchelt, D.R., and Price, D.L. 2002. Genetically engineered mouse models of neurodegenerative diseases. Nat. Neurosci. 5:633-639.

53. Soto, C. 2003. Unfolding the role of protein misfolding in neurodegenerative diseases. Nat. Rev. Neurosci. 4:49-60.

54. Przedborski, S., Vila, M., and Jackson-Lewis, V. 2003. Neurodegeneration: what is it and where are we? J. Clin. Invest. 111:3-10. doi:10.1172/ JCI200317522. 